In color the oxides varied from a chocolate-brown to a light chamois proportional to the equivalents, showing that terbium tends to go to the least soluble end. All the oxides were boiled with water to remove any alkali metal before the equivalents were determined.

$\begin{array}{lcccccc}\text { No. of fraction. } & \text { II. } & \text { III. } & \text { IV. } & \text { VI. } & \text { VII. } & \text { VIII. } \\ \text { Atomic weight....... } & \text { I09.5 } & 95.2 & 89.0 & \text { IO2.3 } & \text { I32.9 } & \text { I22.4 }\end{array}$

2. Separation of erbium from yttrium. The oxide used was very rich in erbium. Twenty-five grams were dissolved in hydrochloric àcid, diluted to about $800 \mathrm{cc}$. and precipitated as in the case of the dysprosium, holmium and yttrium oxides. Two fractions were taken, and these, after converting to oxides and redissolving, were again fractioned. Fraction I gave Fractions III, IV and V, while Fraction II gave Fractions VI and VII. The oxides varied from a rose color to an extremely pale pink. Fraction III, the least soluble, possessed the most color, and Fraction VII, the most soluble, was the palest.

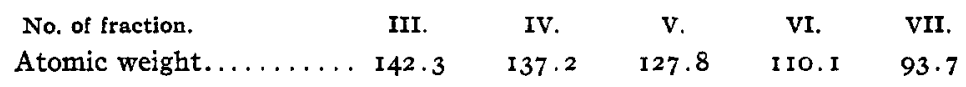

The cobalticyanide method is excellent for the separation of yttrium from erbium and vice versa. The precipitates are very crystalline, and the process can be quickly carried out.

One of the authors and another are investigating the ferricyanides, which are nice crystalline compounds and which differ very considerably in their solubilities. By fractionally precipitating a solution of the nitrates of yttrium and erbium with potassium ferricyanide, a rapid separation is effected.

DuRhaM, N. H.

[CONTRIBUTION FROM THE Chemical LABORATORY OF COLUMBIA UNIVERSITY, NO. 271.]

\title{
AMMONIUM IODIDE, ITS SOLUBILITIES AND THE ABSENCE OF A TRANSITION POINT.
}

By Algxander Smith and Herbert E. Easthack.

Received June 12, 1916.

Wallace ${ }^{1}$ observed no irregularities in the cooling curves of ammonium iodide between $220^{\circ}$ and $-16.5^{\circ}$, and no change under the microscope between $16^{\circ}$ and the sublimation point. He notes that, while the chloride and bromide crystallize in pentagonal icositetrahedra, there is some evidence that above their transition point they are cubical, just like the iodide, and the alkali iodides. He refers also to Tuton's ${ }^{2}$ statement that the molecular volumes of ammonium sulfate and its double salts lie between those of rubidium and caesium, and himself found that, of the am-

1 Centr. Min., 1900, 33.

${ }^{2}$ Z. Kryst., 38, 602 (I904); 4I, 32I (I906). 
monium halides, only the iodide showed this relation. Wallace concluded, therefore, that the transition point of the iodide, if there is any, must lie below - $16.5^{\circ}$, and that the ordinary form of the salt is the one stable above this point.

Although the transition points of the chloride and bromide are high, the transformations on cooling are sluggish. It seemed possible, therefore, that the iodide might possess a transition point below the temperature at which it is ordinarily crystallized from solution, and that, on account of the low temperature of transition, the point might have escaped notice. Definite information being necessary for other work being done in this laboratory, heating and cooling curves were made, without result. The solubility curve of ammonium iodide in water was then determined from - $19^{\circ}$ to $136^{\circ}$. Except for one measurement by Eder ${ }^{1}$ at $15^{\circ}$, and three analyses of the cryohydrate at $-27.5^{\circ}$ by Guthrie, ${ }^{2}$ the literature contains no solubility measurements with this salt. The continuity of our solubility curve shows conclusively that, at one atmosphere pressure, no transition point exists between the above-mentioned temperatures. Considering that the transition point of the chloride is higher than that of the bromide, and the comparative ease with which a transition point, if it existed, could have been observed at higher temperatures, the solubility curve of the iodide was not carried above the transition point of the bromide.

Solubility Measurements.-The ammonium iodide was recrystallized twice from distilled water, was washed with alcohol and ether, and was heated for ten hours at $115^{\circ}$ in an air bath to expel volatile impurities. It was perfectly white. The method exployed was identical with that used by us with ammonium bromide. ${ }^{3}$ For the points below $0^{\circ}$, an alcohol bath, cooled by a freezing mixture, was employed. By immersing the sealed bulb containing the ammonium iodide and water, for a few seconds, in a mixture of solid carbon dioxide and ether, the minute crystals, required for determining the equilibrium points when approached from below, were obtained. Although more time was needed for reaching equilibrium at the low temperatures, the saturation temperatures could be determined $\pm 0.5^{\circ}$. In the tables, the solubilities are in grams of $\mathrm{NH}_{4} \mathrm{I}$ per $100 \mathrm{~g}$. water.

Eder's determination at $15^{\circ}$ ( $167 \mathrm{~g}$.) lies very close to our curve. Guthrie's analyses of the cryohydrate at $-27.5^{\circ}$ are so erratic that two of his determinations fall above, while the third falls below the extension of our curve.

\footnotetext{
1 Dingler's Polytech. J., 221, 189 (1876).

2 Phil. Mag., [4] 49, 213 (1875).

3 This JournaL, 38, I 26 I (1916).
} 
Table I.-Soztbilities of $\mathrm{NH}_{4}$ I in AQ-OBSERvations.

$\begin{array}{cccccc}\text { Temp. } & \text { Solty. } & \text { Temp. } & \text { Solty. } & \text { Temp. } & \text { Solty. } \\ -19^{\circ} & \text { I36.7 } & 32.2^{\circ} & \text { I83.4 } & 93.8^{\circ} & 243.9 \\ -6 & 148.6 & 47.2 & 197.1 & 110.5 & 262.4 \\ +6.4 & 160.2 & 55.5 & 204.3 & 135.0 & 292.1 \\ 10.1 & 163.2 & 61.3 & 210.3 & 136.0 & 294.5 \\ 25.0 & I 76.7 & 70.8 & 219.6 & \ldots \ldots & \ldots \ldots \\ 29.6 & \text { I8I.2 } & 80.8 & 229.3 & \ldots \ldots & \ldots \ldots\end{array}$

TABLE II.-SOLUEILITIES OF $\mathrm{NH}_{4} \mathrm{I}$ IN AQ AT Rounded TeMps.

$\begin{array}{rccccc}\text { Temp. } & \text { Solty. } & \text { Temp. } & \text { Solty. } & \text { Temp. } & \text { Solty. } \\ -20^{\circ} & 136.0 & 25^{\circ} & 176.8 & 80^{\circ} & 228.8 \\ -10 & 145.0 & 30 & 181.4 & 100 & 250.3 \\ 0 & 154.2 & 40 & 190.5 & 120 & 273.6 \\ 10 & 163.2 & 50 & 199.6 & 140 & 299.2 \\ 15 & 167.8 & 60 & 208.9 & \ldots & \ldots \ldots \\ 20 & 172.3 & 70 & 218.7 & \ldots & \ldots \ldots\end{array}$

Summary.-The solubilities of ammonium iodide have been measured between $-19^{\circ}$ and $\mathrm{I} 36^{\circ}$.

The points lie on a single smooth curve, thus confirming Wallace's conclusion regarding the non-existence of a transition point within the same range of temperatures.

Nichols Laboratories OF INORganic Chemistry, Columbia University, New York City.

\section{NOTE.}

A Non-Spattering Wash Bottle.-To avoid spattering at the tip of the nozzle of the ordinary wash bottle the principle of raising the watertable of the wash bottle slightly above the level of the tip of the nozzle has been adopted so that "back action" will not take place and the nozzle tube will remain permanently full of water.

A careful study of the diagram will make the principle clear. While in use the thumb is held over the pressure release $D$, the water is forced up through the tube $\mathrm{C}$ till the water-table indicated, has been reached, the water level being maintained by the stopper $F$. The nozzle works the same as though the wash bottle were full up to the raised water level. Before releasing the pressure from the mouth piece the thumb is taken off the tube $\mathrm{D}$ so that the height of the water-table in $\mathrm{A}$ may be insured and to prevent "back action" through $B$.

In construction the following details are important:

I. Make D $5 \mathrm{~mm}$. or as large as possible to afford a quick release of pressure, having it project only to the bottom of the small cork in A.

2. The size $(4 \mathrm{~mm}$.) and length of $B$ are not important just so the bottom projects an inch or so below the water-table.

3. The stopper $\mathrm{F}$ should be near the bottom of $\mathrm{A}$ for best results. 